\title{
Enriched Blended Learning through Virtual Experience in Microprocessors and Microcontrollers Course
}

\author{
Deepa $\mathbf{M}^{1}$, Reba $\mathbf{P}^{2}$, Santhanamari $\mathbf{G}^{3}$ Susithra $\mathbf{N}^{4}$ \\ Department of Electronics and Communication Engineering \\ PSG Institute of Technology and Applied Research, Coimbatore, India \\ 12deepa.mohanram@gmail.com \\ ${ }^{2}$ rebasatheesh@gmail.com \\ ${ }^{3}$ santhanam88guru59@gmail.com \\ ${ }^{4}$ nsusithra90@gmail.com
}

\begin{abstract}
Microprocessors and microcontrollers is a course that demands concurrent delivery of pragmatic and dogmatic approaches to the students in order to ensure effective learning. Online sessions and active learning for such courses pose challenges to both teachers and students, especially during this pandemic period. In order to combat these challenges, and to kindle the interest among the students in learning the course, a new methodology which supports blended learning through virtual experience is presented in this paper. The proposed methodology was implemented for the third year engineering students of circuit branches. This paper highlights the effectiveness of using open source emulating environments like Edsim51 and EMU8086 for providing a virtual laboratory experience to the students. These virtual environment provides a complete visualization of the internal functionality of the microprocessor/microcontroller architecture, and also enhances practical exposure of the students. In order to further augment the students' affinity towards the course, the teacher adopts different pedagogical approaches, which is best suited for ICT based blended learning in the online teaching environment. The assessment of this virtual experience is carried out using different online assessment components such as quizzes, assignments as concept maps/videos shared by the students, mini projects etc. Based on the assessment results, an analysis is carried out and it shows significant improvement in student engagement, in depth understanding of the course and improvement in programming skills of the students. Thus, this experience not only acts as a countermeasure to the lack of real time laboratory sessions but also promotes 'understanding by doing', which seems almost impossible during this pandemic situation.
\end{abstract}

Keywords: Online learning, live coding, blended learning, virtual experience, microprocessor and microcontroller

\section{Deepa M}

Department of ECE, PSG Institute of Technology and Applied Research, India

deepa.mohanram@gmail.com

\section{Introduction}

Embedded microcontrollers and microprocessors are extensively becoming popular and ubiquitous in this modern era due to their widespread applications ranging from small toys to deep space devices [1]. Most of the electronic systems are centred on embedded systems with microprocessors, microcontrollers and sensors. Millions of devices that are connected in the IoT environment are also embedded with a microcontroller/microprocessor, like, more than 100 microprocessors in a typical car; and around 5 to 10 microprocessors inside a smartphone, etc. The performance of these embedded systems are greatly defined by the digital data processing capability of the microprocessors. The innumerable devices with embedded processors used in daily life necessitate the blooming of this industrial sector [2]. Hence, it is very important to emphasize the importance of Microprocessors and microcontrollers courses to the students and help them in building the necessary skills required to make them industry ready.

Embedded systems require a thorough theoretical understanding of the underlying microprocessors and microcontrollers (both in terms of hardware and software). It also requires a concurrent practical exposure through hands-on experience. Traditional laboratories are equipped with microcontroller/microprocessor development kits along with their supporting software. However, such kits cannot be leveraged to suit the needs of this pandemic situation and so virtual laboratory environments have become a dire need of the hour. These virtual experiences are provided to the students with the help of the integrated Information and Communication Technologies (ICT) and their related tools. In the past few decades of recent advancements, ICT shows an exponential growth by providing a wide variety of new communication capabilities to the society and it has become an integral part in our daily life. ICT is a collective term that covers all types of communication devices ranging from simple hardware to high speed networks with different related services and applications. It has transformed the entire world into a global village where people can communicate with each other even if they are miles apart. With the help of ICT technology, information can be accessed through telecommunications, witnessing revolution in the education field by providing education to everyone, anywhere, even in remote locations. ICT provides access to a wide pool of learning resources and helps in tracking the recent technological advancements easily. It helps every individual to search, explore, learn, relearn, investigate, share and present their learnings, skills, ideas and experiences. Thus, ICT plays an indispensable role in 
the field of education, showing a spiking progress in the evolution of the teaching learning process. This supports the famous saying by Swami Vivekananda, "If people cannot reach schools, schools should reach them" [3].

In addition to the above said advantages, ICT provides more autonomy in learning and students can learn at their own pace. However, the internet has enormous content and students are in need of a facilitator who can guide them through the learning process. Moreover, ICT without an instructor leads to lack of development of cognitive, verbal and nonverbal communication skills. The psychological parameters like feelings, emotions and motivations provided by the facilitator and the peers, kindles positive vibrations of the students, thereby enhancing their learning experience. Thus, adopting ICT does not eliminate the role of teachers completely, instead the teachers act as facilitators and moderators of the modern learning environment. "Integration of ICT in teaching and learning is not a method, rather it is a medium in which a variety of methods, approaches and pedagogical philosophies may be implemented" [4].

This necessitates the employment of an ICT based instructional strategy, a new pedagogical method called enriched blended learning experience for fruitful student engagement and efficient content delivery. Blended learning is an educational approach which utilizes the online resources as an enriched virtual learning environment, more suitable to the pandemic era prevailing currently. In the blended learning approach, the traditional face-to-face learning is combined with e-learning activities. It acts as a personalized online learning assistance for students, providing a more flexible learning atmosphere and permits access to the learning materials at any time and from any geographical location [5]. It serves as the best aid to the students with flexibility to revisit the learning materials and providing them the opportunity to replay the video recordings available in the form of e-learning resources. Thus, blended learning creates an interest and motivation to learn and also supports autonomous learning and thereby creating a responsible and positive attitude towards the course. Overall, blended learning methods promote increase in student engagement during the sessions, increase in student satisfaction and improvement in student learning outcomes.

This paper presents an enriched blended learning experience with a virtual laboratory environment suitable for the current pandemic situation, and it was implemented for the course Microprocessors and Microcontrollers. The experience mainly focuses on effective student engagement and learning, providing a highly motivated environment for kindling the interest towards embedded system development.

\section{A. Related Works}

[6] highlights the importance of embedded systems domain and it provides research results on framing curriculum for the embedded system course. Most of the education literature highlights the importance of gaining in-depth understanding of engineering fundamentals, delivering the technical content effectively and preparing the students for the future technical jobs [7]. The authors in [8] and [9] quoted Project Based Learning (PBL) as the best method for accomplishing the learning outcomes of embedded system course. They have also shown that, several other skills such as problem-solving skills, team skills etc. could also be gained by practicing the PBL approach. Also, PBL could support self-directed learning but it requires suitable tools to guide the students through the process. In [10], the authors explained the use of an emulator as a virtual tool for learning ARM based processor. In their literature, they showed that the students are more interested and they felt very easy in learning the concepts using this tool. Similar types of learning environments are also utilized for other courses. All these literature highlighted significant improvements in students' academic performance and overall satisfaction. [8]-[10] focuses entirely on a hands-on training/laboratory experiences and does not provide inputs on integration of both theory and lab sessions. [11] highlights the delivery of content for Digital Systems course, along with laboratory component. In this paper, a holistic view of delivering a laboratory oriented course along with theory session is presented in accordance with the current pandemic situation.

\section{B. Course Overview}

The course on Microprocessors and Microcontrollers is offered as a core subject to the undergraduate students of Computer Science and Engineering programme during their fifth semester (third year), comprising of 60 students. The curriculum for the course is provided by Anna University. This course is intended to introduce the 8086 microprocessor and 8051 microcontroller architecture, instruction set, and interfacing various peripherals like stepper motor, switches, 7 segment LED etc., The laboratory component of this course emphasizes on assembly language programming (ALP) and provides an hands-on experience to interface the different Input/Output (I/O) devices to the microprocessor or microcontroller using the system development kit (SDK).

The learning outcomes/Course Outcomes (CO) of this course are listed below. After successful completion of this course, the students will be able to,

CO1 Write Assembly language programs for microprocessors by applying digital concepts.

$\mathrm{CO} 2$ Illustrate communication and bus interfacing concepts in a multiprocessor environment.

CO3 Elaborate how different peripherals are interfaced with Microprocessor and Microcontroller for system design.

CO4 Illustrate the architecture, instruction set and in-built peripherals of 8051 .

CO5 Design microcontroller based system for real time application.

\section{Traditional Approach}

The Microprocessors and Microcontrollers course is allotted a total of four contact sessions ( 3 theoretical sessions and one tutorial session each spanning an hour) per week. The traditional method of content delivery mainly focuses on the theoretical/dogmatic approach by chalk and talk. The 
students tend to get deviated easily from the session due to the monotonous delivery. They also find it hard to visualize the architecture and lack proper understanding of the instruction set during the theoretical sessions. Few assignments and quizzes are given to students as part of continuous assessment.

The laboratory component of this course is allotted four hours per week, and the student has to wait for the practical sessions in order to conceptualise his/her understanding of the topics covered in the theory sessions. The students are split into groups of two or three members in order to carry out the practical exercises. Laboratory classes help the students in getting a complete understanding of what they learnt in the theoretical sessions. However, the hardware available in the laboratory is not allowed to be taken outside the laboratory without any prior permission and formalities. Though the four hour laboratory sessions provide a comprehensive exposure towards the concepts, the resources may not be sufficient to cater to the individual learning needs. Moreover, since the predominant mode of teaching is online during this COVID-19 pandemic, students are deprived of laboratory access and there is a void for hands-on experience of practical situations.

\section{Enriched Blended Learning Approach}

In traditional teaching methodology, the students remain passive most of the time and in-class learning is not so significant, since the teachers primarily focus on transfer of knowledge rather than focusing on students' learning outcomes. A typical student's attention span is only 15 minutes after which they tend to get distracted. The teachers need to adopt different pedagogical approaches to retain the attention of the students after their attention span.

In recent times, new teaching learning practices and pedagogical approaches are developed to encourage the active participation of the students in the classrooms. One such method is 'learning by doing' which enhances theoretical knowledge with practical exposure for the courses like microprocessors and microcontrollers. However, this practical exposure requires hardware kits which cannot be accessed by all students and at all times, especially due to the prevailing pandemic situation.

Based on the vision of University Grants Commission (UGC) and Ministry of Human Resources and Development (MHRD), the higher education institutions motivate the teachers and students to adapt to use ICT tools through online teaching learning platforms. Also, Digital learning/Online learning is the choice of the hour, since it provides a feeling of psychological safety during the COVID-19 period. Since many institutions have already adapted to a blended learning approach through LMS and since most of the stakeholders have different ICT devices, it is not much daunting to adapt to this new paradigm.

Conduct of separate theoretical and practical sessions through online mode pose several issues, and it is not satisfactory for both students as well as faculty. In order to combat such issues, a concurrent simulation based blended learning approach was suggested to enhance individual learning experience and to promote effective understanding and visualization of the concepts. This method incorporates an emulator based environment during the online theoretical sessions. Software emulator is a hardware look-alike environment, which is best suited for self-paced practice alongside virtual lab based theory sessions. Time is not a constraint at all, due to the availability of hand-held devices. While the faculty demonstrate and facilitate, the students are also encouraged to use the emulators to write codes paving way for 'immediate learning by doing'. The students are also motivated to share their screens during the theoretical sessions and online debugging is done with the help of peer support facilitated by the faculty.

Edsim51 and EMU8086 are the two emulators used for this course. The virtual experience obtained through these emulators throws more light into the students' perception and helps them to picturize the concepts of the microprocessor and microcontroller. The students are also encouraged to develop a complete application using the emulator with the supporting peripherals like stepper motor, switches, 7 segment LED, which are integrated in the emulating environment in order to promote their higher order thinking skills. By adopting this strategy, the students' engagement is improved and it also provides them a sense of responsibility and accountability among the students. Yet, this cannot replace the laboratory hands-on experience. This enriched virtual laboratory option for a blended learning approach not only provides a one stop solution for the pandemic situation, but also serves as an apt method for contact in-person teaching sessions. More explanation of these emulators and emulator based learning (EBL) is provided in section 3B. The blended learning approach for online sessions are organised as one hour sessions for theory and tutorial and one and a half hour sessions for laboratory demonstration, incorporating various pedagogical approaches like quizzes, polls, assignments, flipped laboratory model in addition to Emulator Based learning (EBL) to hold the attention of the students by maximizing student engagement and minimizing monotonous lecturing. The detailed micro plan for the online theory/laboratory sessions are provided in Table 1.

Online platforms like Google Meet, Zoom, Cisco Webex, etc., are used for video conferencing for the delivery of online classes. The students login to the respective Google Meet at the prescribed timings. In order to make effective online presentations, software tools like Jam Board, Open Board, Chalk and talk with video camera etc., were used. Table 2 also highlights the ICT tools used for different pedagogical methods during the enriched blended learning approach.

\section{A. Micro plan for an Enriched Blended learning session}

The enriched virtual model of blended learning provided to the students can be categorized into three phases namely: Pre-class, In-class and Post-class. Fig. 1 highlights the blended components practiced in the different phases of the enriched blended learning approach for the Microprocessors and Microcontrollers course. 
Table 1: Micro Plan for the Delivery of Course Content through Enriched Blended Learning (BL) Approach

\begin{tabular}{|c|c|c|c|c|}
\hline $\begin{array}{c}\text { Instructional } \\
\text { events }\end{array}$ & $\begin{array}{c}\text { BL } \\
\text { phase }\end{array}$ & Description & Duration & Platform \\
\hline $\begin{array}{l}\text { Stimulating recall } \\
\text { of prerequisites and } \\
\text { provide abstract } \\
\text { foundation to the } \\
\text { topic }\end{array}$ & 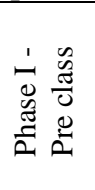 & $\begin{array}{l}\text { - Revision of prerequisite terminologies and principles } \\
\text { - Graphical representations to provide an abstract view } \\
\text { of the forthcoming concept } \\
\text { - Reference material presented as video with } \\
\text { integrated quiz }\end{array}$ & $\begin{array}{l}\text { Students' } \\
\text { pace }\end{array}$ & Google Classroom \\
\hline \multirow{9}{*}{$\begin{array}{l}\text { Presenting the } \\
\text { concept in an } \\
\text { online class }\end{array}$} & \multirow{8}{*}{ 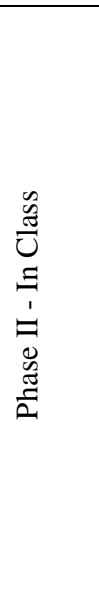 } & Brief recap of key concepts from the previous class & 2 mins & Google meet \\
\hline & & Introducing the session learning objective & 5 mins & Google meet \\
\hline & & $\begin{array}{l}\text { Explanation of the new concepts and principles } \\
\text { through different approaches }\end{array}$ & 20 mins & $\begin{array}{l}\text { PowerPoint, Wacom, Jamboard, } \\
\text { Elmo projector, Video camera }\end{array}$ \\
\hline & & Short Live Quizzes and Polls in between the class & $5 \mathrm{~min}$ & Poll master, Quizzes.com \\
\hline & & $\begin{array}{l}\text { - Visualization of the concept and hardware } \\
\text { functionality with Emulator environments } \\
\text { - Simulation practice by Inquiry and Live Coding } \\
\text { methods }\end{array}$ & 20 mins & Edsim51/EMU 8086 \\
\hline & & One Minute feedback & $1 \mathrm{~min}$ & Google forms \\
\hline & & $\begin{array}{l}\text { - Assignment presentation - Students demonstrate } \\
\text { their assignments through a screen sharing } \\
\text { - Student - teacher interaction to get clarify their } \\
\text { doubts }\end{array}$ & 5 mins & $\begin{array}{l}\text { Google meet by sharing } \\
\text { students' screen }\end{array}$ \\
\hline & & $\begin{array}{l}2 \text { - Minute Summary - Students recall, recap and } \\
\text { explain the concept in their own words }\end{array}$ & 2 mins & Google meet (unmute and talk) \\
\hline & \multicolumn{2}{|r|}{ Total } & \multicolumn{2}{|l|}{60 mins } \\
\hline $\begin{array}{l}\text { Performance } \\
\text { assessment and } \\
\text { enhancing } \\
\text { knowledge } \\
\text { retention and } \\
\text { transfer }\end{array}$ & 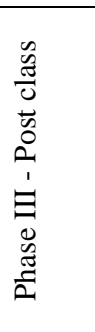 & $\begin{array}{l}\text { - Students refer to recorded videos of online classes if } \\
\text { they have doubt or if they have missed the class } \\
\text { - Open ended discussion through questions and } \\
\text { discussion forums to support peer to peer interaction } \\
\text { and peer learning } \\
\text { - Programing assignment using emulators/simulators } \\
\text { as a post class activity } \\
\text { - Offline quizzes and assignments which promote } \\
\text { higher order thinking capabilities }\end{array}$ & $\begin{array}{l}\text { Students' } \\
\text { pace } \\
\text { within the } \\
\text { deadline }\end{array}$ & Google Classroom \\
\hline
\end{tabular}

1) Phase I (Pre-class): During the pre-class activities, in order to recall the prerequisite terminologies and principles, and to get an abstract understanding of the forth coming class, the related references are presented as videos and graphical representation. This provides a foundation for next level learning. The video contents are integrated with quizzes and these quizzes are not considered for grading.

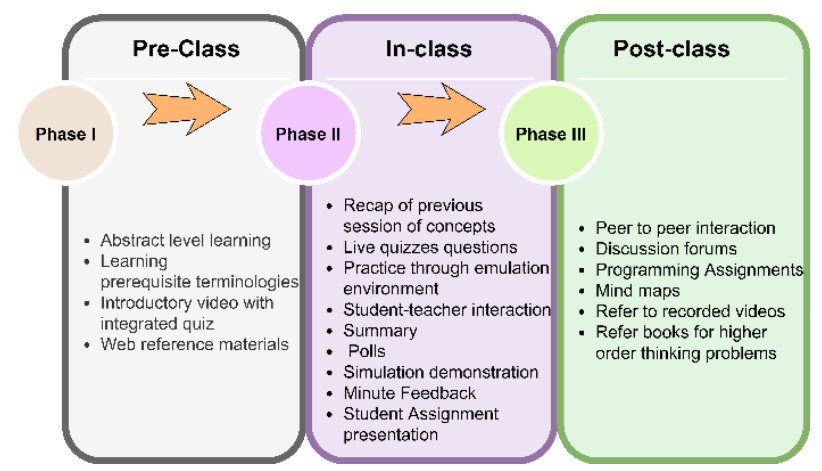

Fig. 1: Different phases of the enriched blended learning approach
2) Phase II (In-Class): During the live online session, new subject matter is presented to the students with suitable numerical examples, analogies and illustrations wherever necessary. The conceptualisation of the terminologies and hardware functionality of processors/controllers are demonstrated with the help of live coding techniques using emulators. The students are also encouraged to present their assignments during the online sessions for peer encouragement and interaction. Poll questions are posted during the sessions to access students' understanding.

3) Phase III (Post-Class): The post-class performance assessment activities are provided to the students in the form of quizzes and programming assignments. The submissions are managed with the help of LMS platforms like Google classroom and the simulation experiments are provided in multimedia formats (Screen capture video/screenshot images) by the students for assessment. The teacher also initiates peer learning/peer interaction by posting open ended questions in discussion forums. 
Table 2 compares the different aspects followed in traditional teaching with that of the blended teaching learning approach.

\section{B. Emulator Based Learning (EBL)}

The conventional way of teaching microprocessor and microcontroller course makes the students to learn, by imaging the internal functionality of processor/controller chip; And during the laboratory sessions the students use hardware educational kits, (8086 SDK (System Development Kit)) shown in Figure 2, to perform the experiments and they could only able to see the execution results and I/O transfer of the program they have run on it. While, the educational emulator based learning makes the students visualize both internal and external functionality of processor/controller chip.

Table 2: Traditional versus Blended Learning Aspects/Components

\begin{tabular}{|c|c|}
\hline $\begin{array}{l}\text { Traditional Mode } \\
\text { (Per Week) }\end{array}$ & $\begin{array}{l}\text { Blended learning in online } \\
\text { classes (Per Week) }\end{array}$ \\
\hline $\begin{array}{l}3 \times 1 \mathrm{hr} \text { for face-to-face } \\
\text { lecture classes } \\
1 \mathrm{x} 1 \mathrm{hr} \text { for tutorial session } \\
\text { - Problems are solved in a } \\
\text { peer learning environment } \\
\text { Peer group interaction is } \\
\text { improved }\end{array}$ & $\begin{array}{l}\text { - } 3 \times 1 \mathrm{hr} \text { for theory sessions } \\
\text { - } 2 \times 1 \mathrm{hr} \text { for tutorial sessions } \\
\text { - Emulator based learning } \\
\text { - Online polls, quizzes } \\
\text { - } 20 \text { minutes lecture } \\
\text { - Doubt clarification } \\
\text { - One-minute feedback }\end{array}$ \\
\hline $\begin{array}{l}\text { - } 1 \text { x } 4 \text { hr laboratory class } \\
\text { - Demonstration of } \\
\text { experiments by faculty } \\
\text { - Experiments are conducted } \\
\text { by students organised into } \\
\text { groups }\end{array}$ & $\begin{array}{l}\text { - } 1 \times 11 / 2 \text { hr laboratory class } \\
\text { - Video demo of experiments } \\
\text { using hardware are posted } \\
\text { in google classroom } \\
\text { (Flipped laboratory model) } \\
\text { - Experiments are practiced } \\
\text { by students individually } \\
\text { using virtual tools }\end{array}$ \\
\hline $\begin{array}{l}\text { Quiz tests and/or assignments } \\
\text { are conducted after the } \\
\text { completion of each chapter. }\end{array}$ & $\begin{array}{l}\text { - A timed quiz at the end of } \\
\text { each session. } \\
\text { - } 2 \text { online assignments for } \\
\text { each lesson. } \\
\text { Drawing concept map for } \\
\text { each lesson is one of the } \\
\text { assignment }\end{array}$ \\
\hline $\begin{array}{l}\text { Programming with hardware } \\
\text { peripherals is done in the } \\
\text { laboratory sessions }\end{array}$ & $\begin{array}{l}8086 \text { microprocessor and } \\
8051 \text { microcontroller are } \\
\text { programmed using } \\
\text { EMU8086 and Edsim51 } \\
\text { emulators (free open source } \\
\text { tools) }\end{array}$ \\
\hline $\begin{array}{l}\text { No programming assignment } \\
\text { is given to students as a part } \\
\text { of theory session }\end{array}$ & $\begin{array}{l}\text { Two programming } \\
\text { assignments for each } \\
\text { lesson } \\
\text { Students submit a short video } \\
\text { of the application developed } \\
\text { using emulators }\end{array}$ \\
\hline $\begin{array}{l}11 / 2 \text { hours descriptive exam } \\
\text { - Closed book test with few } \\
\text { GATE questions } \\
\text { - Exam halls invigilated by } \\
\text { faculty }\end{array}$ & $\begin{array}{l}11 / 2 \text { hours descriptive exam } \\
\text { Open book test with higher } \\
\text { order thinking questions } \\
\text { (questions from GATE, } \\
\text { ISRO, and other } \\
\text { competitive exams) }\end{array}$ \\
\hline
\end{tabular}

Also, these tools help in demonstrating the functionality of microprocessors/microcontrollers to students and thereby promotes more interest in learning during the online classes. It also kindles the interest among the students practice real time application development.

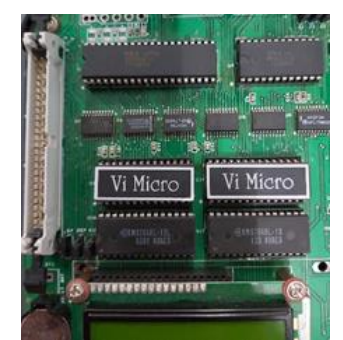

Fig. 2: 8086 SDK (System Development Kit)

1) EMU 8086: EMU8086 integrates the program development tools like advanced source editor, assembler, disassembler, software emulator (Virtual PC) with debugger and virtual modules inbuilt in processors like ALU, memory, stack, flags and symbol table etc., [12]. The EMU8086 simulation environment is shown in Fig. 3.

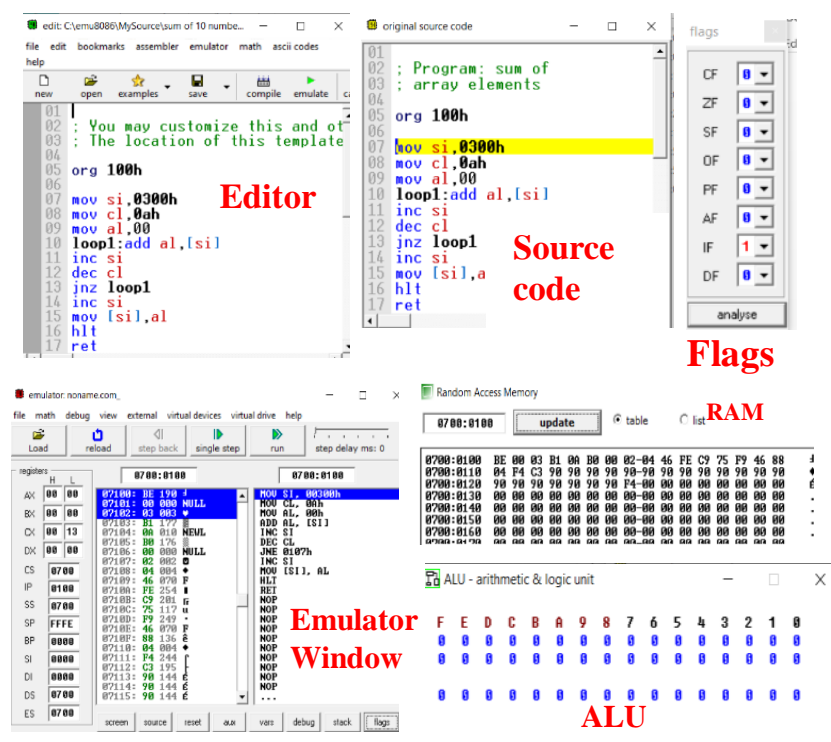

Fig. 3: EMU8086 emulator tool window and the user interface

The significant features of EMU8086 are

- Users can view Arithmetic \& Logical Unit (ALU) that shows the internal functioning of the Central Processor Unit (CPU).

- Users can watch registers, flags and contents of memory locations while the program is being executed with step mode run (Debugging).

- EMU8086 has inbuilt virtual peripherals like stepper motor, keyboard, LED display etc. to develop simple applications.

- EMU8086 has an easier syntax. It makes the process of learning and practicing an Assembly Language Programming (ALP) easy for the beginners.

- Since emulators run programs on a virtual computer system, real hardware such as hard-drives and memory are not accessed and also the debugging process becomes easy.

2) Application development in EMU8086: The students were introduced to the emulating environment EMU8086 during 
the theory sessions, and they were mentored to write and execute simple ALP such as finding the factorial, searching, sorting etc. as per the curriculum.

The conventional way of application development requires that all the hardware components are available and the perfect interconnection between the components is required, to make the execution of programs successful. Also, facilitating all the students to implement their ideas in a hardware based development kit is difficult for the teachers

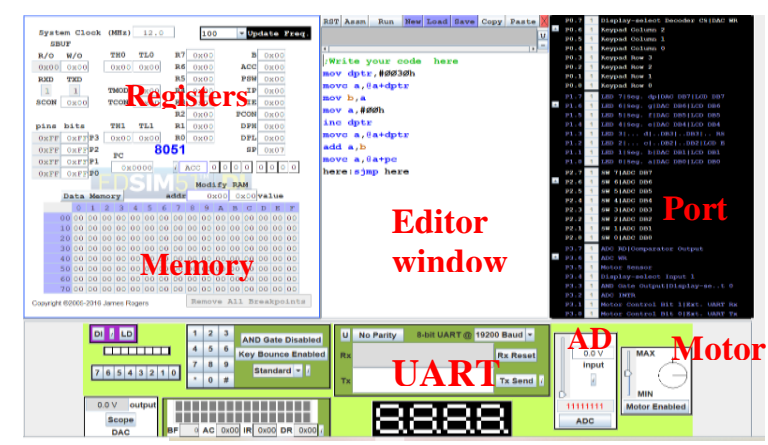

in this pandemic situation. In this situation, this emulator plays a vital role in making the students think and develop simple applications that transform even the online environment into an application development environment. The students can write code at the ease of their home environment and share the same with the teachers for any doubt clarifications. Since visual interface is very easy to work with, in EMU8086, the students are motivated to develop simple applications with stepper motor, keyboard and printer. The screenshots of output of two such applications developed by the students namely traffic light controller and temperature sensing using thermometer with digital output are shown in Fig. 4 and Fig. 5 respectively. The students are also motivated to take short video clippings of the application execution and submit as a mini project. The teachers are able to appreciate and acknowledge the work of students through their video portrayal.

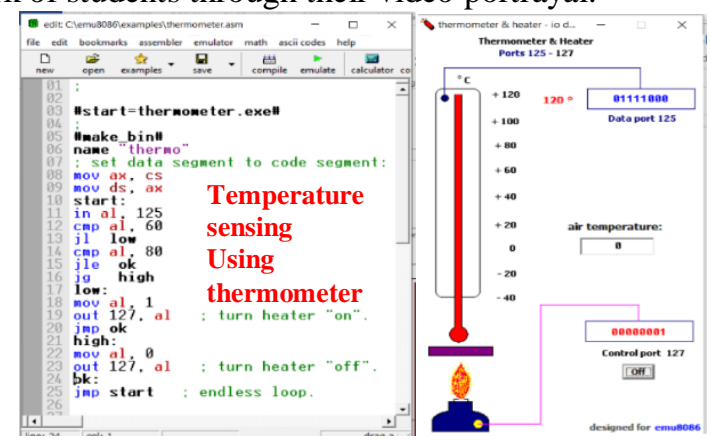

Fig. 4: Temperature measurement application implemented using EMU8086

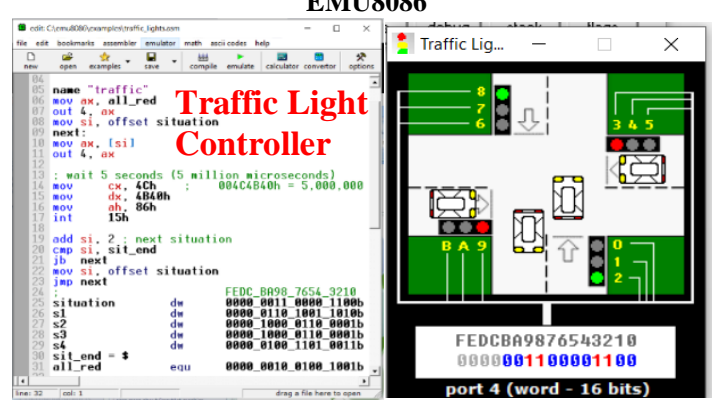

Fig. 5: Traffic light controller application implemented using EMU8086

3) Edsim51: The emulator EdSim51 is used to teach and demonstrate the 8051 microcontroller [13]. Edsim51 helps the students to learn and write programs to exercise the 8051 microcontroller. A screenshot of EdSim51 is shown in Fig. 6. Owing to the enormous bit handling capability of microcontrollers, students become accustomed to the use of different bit handling instructions needed for control operations and branch instructions that make up the 8051 instruction set complete.

Fig. 6: Edsim51 tool for practicing 8051 microcontroller based programs

4) Application development in Edsim51: As the students have gained expertise in developing simple application programs in the emulating environment, they are assigned a team project with the idea of using the peripherals available in the emulating environment. Timers, ports and interrupts are some of the important supporting peripherals in application development. The basics of interfacing based application development are demonstrated in the theory session and the students are also able to follow the same steps to mimic the functionality. Some of the demonstrations which were conducted in the online classes are depicted in Fig. 7. The fig. 7 (a) shows the screenshot of the output after interfacing (Digital to Analog Converter) DAC to generate the staircase signal and fig. 7(b) shows the interfacing of seven segment display and LEDs to display a character/pattern.

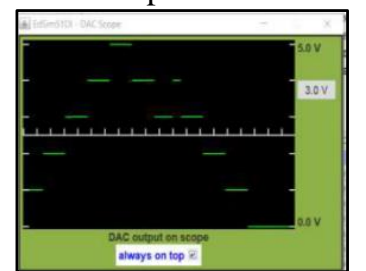

(a)

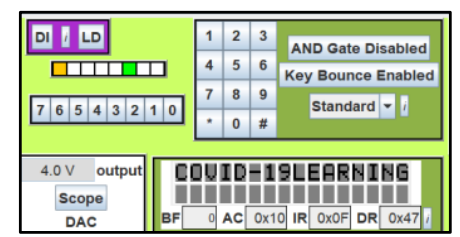

(b)
Fig. 7(a) Interfacing DAC to 8051 microcontroller to generate the staircase signal, (b) Interfacing of seven segment displays and LEDs to display 'COVID-19LEARNING'

\section{Evaluation of Course Delivery}

The evaluation of effectiveness of course delivery can be gauged in terms of the following factors namely: Student Engagement, Academic Performance, Self-Evaluation by faculty members, Students' Perception and Feedback.

A. Student Engagement

The effective student engagement in the online learning environment is assessed based on different components and their observations on the student group are listed in Table 3.

\begin{tabular}{|l|l|l|}
\hline \multicolumn{1}{|c|}{ Table 3: Assessment of Student Engagement } \\
\hline Criteria & \multicolumn{1}{|c|}{ Comments } & \multicolumn{1}{c|}{ Observation } \\
\hline Punctuality & $\begin{array}{l}\text { Logging into the } \\
\text { Google meet session } \\
\text { well before the }\end{array}$ & $\begin{array}{l}92 \% \text { of the students } \\
\text { login on-time for the } \\
\text { online classes, which } \\
\text { was collected using the } \\
\text { session begins or on- } \\
\text { time }\end{array}$ \\
& & $\begin{array}{l}\text { Google Meet } \\
\text { Attendance Collector } \\
\text { add-on. }\end{array}$ \\
\hline
\end{tabular}




\begin{tabular}{|c|c|c|}
\hline $\begin{array}{l}\text { Assignment } \\
\text { submission }\end{array}$ & $\begin{array}{l}\text { Timely Submission of } \\
\text { assignments, quizzes } \\
\text { and programming } \\
\text { tasks } \\
\text { Well documented } \\
\text { assignment with } \\
\text { attractive multimedia } \\
\text { content } \\
\text { Response to } \\
\text { comments posted by } \\
\text { faculty }\end{array}$ & $\begin{array}{l}78 \% \text { of students } \\
\text { submitted the } \\
\text { assignments on/before } \\
\text { the deadline } \\
30 \% \text { of the students } \\
\text { submit their } \\
\text { assignments with clear } \\
\text { documentation and } \\
\text { images/videos }\end{array}$ \\
\hline Atten & $\begin{array}{l}\text { Presence and active } \\
\text { participation } \\
\text { throughout the } \\
\text { session }\end{array}$ & $\begin{array}{l}95 \% \text { of the students } \\
\text { maintain attendance } \\
\text { records of } 70 \% \text { and } \\
\text { above. }\end{array}$ \\
\hline $\begin{array}{l}\text { Participating } \\
\text { in } \\
\text { discussion } \\
\text { forums }\end{array}$ & $\begin{array}{l}\text { Posting queries and } \\
\text { responding to queries } \\
\text { of peers in the } \\
\text { discussion forum } \\
\text { Taking part in open- } \\
\text { ended discussions }\end{array}$ & $\begin{array}{l}45 \% \text { of the students } \\
\text { reply to } \\
\text { queries/threads and } \\
20 \% \text { of the students } \\
\text { open new threads in } \\
\text { the forum }\end{array}$ \\
\hline
\end{tabular}

The student engagement can also be measured in terms of how frequently they check the Google classroom for the course contents and how frequently he/she interacts with the faculty during the live sessions. It was also seen that the students tend to engage more frequently in the online sessions due to the absence of face-to-face interaction with faculty, in order to establish their contact. They tend to maintain a rapport with the faculty either by answering the questions posed by faculty or responding through the chat box facility.

Dedicated time slots are also allocated among the live lecture schedule to review the student submissions in terms of assignments and quizzes. This encourages the students to interact with the faculty and their peers, thus enhancing the communication skills during the blended learning approach.

\section{B. Academic Performance}

The percentage distribution of marks considered for different assessment components while evaluating each course outcome attainment in traditional as well as enriched blended learning approaches is presented in Table 4. The blended learning has an added component for assessment namely programming assignment due to the absence of faceto-face laboratory practise.

Table 4: Traditional versus Blended Learning Continuous Assessment Components

\begin{tabular}{|l|l|l|l|}
\hline \multicolumn{2}{|l|}{ Traditional method } & \multicolumn{2}{|l|}{ Enriched Blended learning } \\
\hline $\begin{array}{l}\text { Assessment } \\
\text { component }\end{array}$ & Weightage & $\begin{array}{l}\text { Assessment } \\
\text { Component }\end{array}$ & Weightage \\
\hline $\begin{array}{l}\text { Quiz/assignments } \\
\text { (3 Nos.) }\end{array}$ & $20 \%$ & $\begin{array}{l}\text { Quiz tests (10 } \\
\text { Nos.) }\end{array}$ & $20 \%$ \\
\hline $\begin{array}{l}\text { Assignments - } \\
\text { Writing } \\
\text { programs }\end{array}$ & $20 \%$ & $\begin{array}{l}\text { Assignments } \\
\text { (1. Handwritten } \\
\text { assignments } \\
\text { 2. Mind map) }\end{array}$ & $20 \%$ \\
\cline { 3 - 4 } & & $\begin{array}{l}\text { Programming } \\
\text { Assignment } \\
\text { (Coding, execution } \\
\text { and result) (2 Nos.) }\end{array}$ & \\
\hline $\begin{array}{l}\text { Descriptive } \\
\text { (Closed book) }\end{array}$ & $60 \%$ & Open book test & $40 \%$ \\
Exams & & & \\
\hline
\end{tabular}

The traditional methodology focuses more on descriptive type of assessment tools with higher weightage than the quizzes/assignment components. The traditional method did not have any separate assessment strategy for assessing the programming skills, since the laboratory sessions were not an integral part of theory sessions and they were separate. Whereas, the online mode of blended learning provides more opportunities for the student in improving his/her in-depth understanding of the subject with the help of more nondescriptive components, and less weightage being provided to the descriptive type of internal assessment. Moreover, the blended learning strategy incorporates more quizzes, assignments, mind maps, and programming assignments as a part of immediate assessment strategy and focuses on questions at higher cognitive levels. This in turn enhances the higher order thinking capability of the student. Some of the live quizzes, polls and pre-class quizzes are provided as ungraded assignments in order to check the understanding of the students before and during the class hours. A sample mind map assignment depicting the topic "Timers, Ports and Interrupts of 8051 microcontroller" presented by a student is shown in Fig. 8 [14].

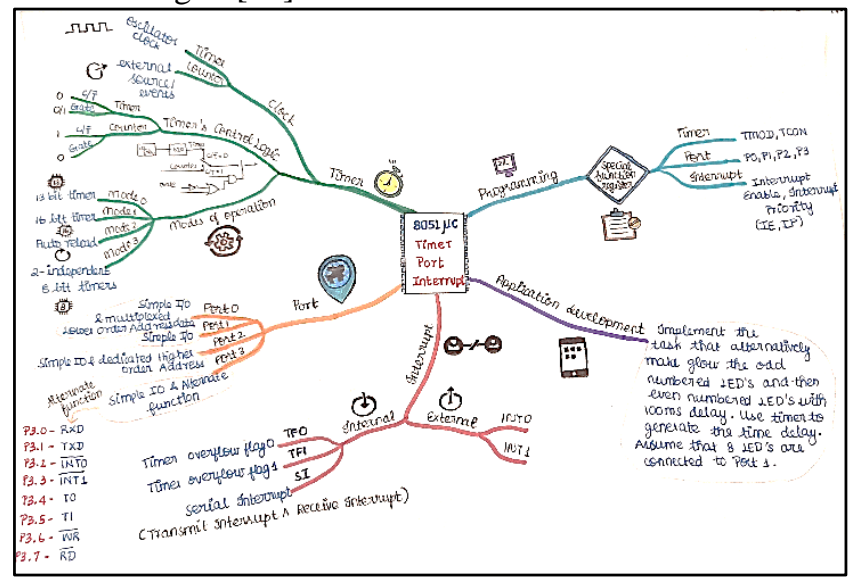

Fig. 8: Mind Map presented by a student for the topic "Timers, Ports and Interrupts of 8051 microcontroller"

The programming assignments were submitted as a short video of the screen capture of the emulator platform showing the working of the application program developed. This greatly improves the internal motivation of the students and also serves as a motivation for other students to bring out the best in them. The frequent assessments conducted through online mode are evaluated immediately and it was found that the overall class average has increased though the minimum and the maximum scores are almost the same. Table 5 shows the mean and median of a sample assignment graded during tradition as well as blended learning sessions.

$\begin{array}{lllll}\text { Table 5: Sample Assignment Grade Comparison (Marks out of 100) } \\ \begin{array}{l}\text { Teaching Learning } \\ \text { Method }\end{array} & \text { Min } & \text { Median } & \text { Mean } & \text { Max } \\ \begin{array}{l}\text { Traditional method } \\ \text { Enriched Blended }\end{array} & 40.0 & 70.0 & 71.1 & 95.0 \\ \text { learning } & 40.0 & 85.0 & 80.7 & 95.0\end{array}$

A mini project task is allotted to students groups during the progress of the course and at the end of the course, students 
are insisted to submit and make an online presentation on the same as a team. The Performance of mini project task after individual assessment in both teaching learning methods is shown in Table 6. More students have enthusiastically completed the task in the enriched Blended Learning method. This task also improves coding efficiency of the students.

Table 6: Mini Project Completion Rate

$\begin{array}{lccc}\text { Teaching Learning } & \text { Complete } & \begin{array}{l}\text { Partial } \\ \text { Submission }\end{array} & \text { Incomplete } \\ \text { Traditional } & 50 \% & 27 \% & 23 \% \\ \text { method } & (35 / 70) & (19 / 70) & (16 / 70) \\ \text { Enriched Blended } & 66 \% & 20 \% & 14 \% \\ \text { learning } & (46 / 70) & (14 / 70) & (10 / 70)\end{array}$

\section{Self-Reflection}

Owing to prevailing COVID situations, the faculty have been working meticulously in order to maximize the learning outcomes and minimize the student distractions. They have been employing different pedagogical strategies to increase the motivation levels of the student, and thereby enabling a holistic development of the student in terms of increased responsibility and accountability, even in the absence of a face-to-face interaction. The faculty also pay individual attention to the students' needs and clarify their doubts even outside the live lecture sessions. It was also observed that most of the students were able to easily adapt to this learning environment while $5 \%$ of the students were reluctant and they still needed considerable assistance from the faculty members in addition to the live lecture sessions.

\section{Students' perception and feedback}

The students seem to welcome the COVID situation with open minds and they are adapting to the digital era. The students were provided with one minute feedback questionnaire to assess their level of understanding and it is presented in Table 7. The percentage values in Table 7 represents the percentage of students who have rated the particular option.

In the feedback, students have mentioned that they miss the real laboratory sessions yet the live coding compensates the lack of laboratory classes. In one of the messages, a student has mentioned, "In this new normal, with the emulator environment, we can get the real essence of the lab session and are highly helpful in understanding the logic behind the concepts taught in the class. "In another student feedback it was mentioned that, "The quizzes and assignments play a very big role in enhancing my understanding towards the concept. Even if I miss a point, I'm able to analyze that while taking up the quiz and I am able to learn more points regarding the topic."

Table 7: Questionnaire for Students Feedback

\begin{tabular}{|c|c|c|c|c|c|}
\hline \multicolumn{7}{|c|}{ One Minute Feedback } \\
\hline Ratings & $\mathbf{1}$ & $\mathbf{2}$ & $\mathbf{3}$ & $\mathbf{4}$ & $\mathbf{5}$ \\
\hline $\begin{array}{l}\text { The overall online } \\
\text { sessions were } \\
\text { congenial }\end{array}$ & $3.3 \%$ & $5 \%$ & $25 \%$ & $36.6 \%$ & $30 \%$ \\
\hline $\begin{array}{l}\text { Blended learning } \\
\text { approach improved }\end{array}$ & $5 \%$ & $3.3 \%$ & $13.3 \%$ & $25 \%$ & $53.3 \%$ \\
\hline
\end{tabular}

\begin{tabular}{|l|l|l|l|l|l|}
\hline $\begin{array}{l}\text { the in-depth } \\
\text { understanding }\end{array}$ & & & & & \\
\hline $\begin{array}{l}\text { Discussion forums } \\
\text { improved peer group } \\
\text { interaction }\end{array}$ & $1.6 \%$ & $1.6 \%$ & $21.6 \%$ & $30 \%$ & $45 \%$ \\
\hline $\begin{array}{l}\text { Programming } \\
\text { assignments } \\
\text { improved my level } \\
\text { of confidence }\end{array}$ & $6.6 \%$ & $3.3 \%$ & $16.6 \%$ & $46.6 \%$ & $26.6 \%$ \\
\hline $\begin{array}{l}\text { Assignment } \\
\text { presentation serves } \\
\text { as an effective tool } \\
\text { to improve the } \\
\text { communication } \\
\text { skills }\end{array}$ & $6.6 \%$ & $5 \%$ & $20 \%$ & $23.3 \%$ & $45 \%$ \\
\hline
\end{tabular}

*On a linear scale of 1 to 5,5 corresponds to maximum rating

\section{Conclusion}

No lock down will knock down the spirits of learning. It has become uncertain as to when a full classroom face-to-face in-person teaching learning process in a physical classroom will take place in this 'new normal' society again. To keep the learning process going irrespective of situational obstacles, a well-planned and structured ICT based digital learning is essential. In online learning, students were engaged through web based learning management tools and video conferencing applications. Formative assessments through frequent evaluations are required to judge whether the students are on track and to determine whether the pace of Teaching-Learning by the faculty is comfortable. Even though faculty and students could not meet in person, one cannot compromise on the holistic development of the student (equal importance to pragmatic and dogmatic knowledge) and one has to strive to achieve it by all means. Effectiveness of teaching and learning was determined by the understanding of the learner. Most teachers took special care about imparting knowledge to students. But the best teachers paid attention to the relational aspect of teaching. They took time to establish a trusting and caring bond with their students and got to know their students' interests, talents, and needs, which helped them prepare their lessons. In turn, students became more receptive to what was being taught and felt the partnership of the teaching-learning experience. The enriched blended learning aims to serve the same through a blend of synchronous live sessions with programming assignments and live coding through opensource emulating environments. However, additional activities can be included into the above process through gamification.

\section{References}

[1] Balid, W., Abdulwahed, M., \& Alrouh, I. (2014). Development of an educationally oriented open-source embedded systems laboratory kit: a hybrid hands-on and virtual experimentation approach. International Journal of Electrical Engineering Education, 51(4), 340-353.

[2] Chung, H., Long, S., Han, S. C., Sarker, S., Ellis, L., \& Kang, B. H. (2018, January). A comparative study of online and faceto-face embedded systems learning course.

[3] Dhandabani, L., \& Sukumaran, R. (2014, December). Use of ICT in engineering education: A survey report. In 2014 IEEE 
International Conference on Computational Intelligence and Computing Research (pp. 1-5). IEEE.

[4] Garrett, N. (1991). Technology in the service of language learning: Trends and issues. The Modern Language Journal, 75(1), 74-101.

[5] Latchem, C. (2017). Using ICTs and blended learning in transforming technical and vocational education and training. UNESCO Publishing.

[6] Sangiovanni-Vincentelli, A. L., \& Pinto, A. (2005). Embedded system education: a new paradigm for engineering schools?. ACM SIGBED Review, 2(4), 5-14

[7] Felder, R. M., Woods, D. R., Stice, J. E., \& Rugarcia, A. (2000). The future of engineering education II. Teaching methods that work. Chemical engineering education, 34(1), 26-39.

[8] Kim, J. (2011). An ill-structured PBL-based microprocessor course without formal laboratory. IEEE Transactions on Education, 55(1), 145-153.

[9] Calvo, I., Cabanes, I., Quesada, J., \& Barambones, O. (2017). A multidisciplinary PBL approach for teaching industrial informatics and robotics in engineering. IEEE Transactions on Education, 61(1), 21-28.

[10] Cadenas, J. O., Sherratt, R. S., Howlett, D., Guy, C. G., \& Lundqvist, K. O. (2015). Virtualization for cost-effective teaching of assembly language programming. IEEE Transactions on Education, 58(4), 282-288.

[11] Alcaraz, R., Martínez-Rodrigo, A., Zangróniz, R., \& Rieta, J. J. (2019). Blending Inverted Lectures and Laboratory Experiments to Improve Learning in an Introductory Course in Digital Systems. IEEE Transactions on Education.

[12] https://emu8086-microprocessor-emulator.en.softonic.com/

[13] https://www.edsim51.com/

[14] Awati, J. S., Desai, S. S., \& Tope, S. (2020). Mind Mapping: An Effective Teaching Learning Evaluation Tool in Engineering Education. Journal of Engineering Education Transformations, 33, 78-83. 